\title{
Avoidant Personality Disorder
}

National Cancer Institute

\section{Source}

National Cancer Institute. Avoidant Personality Disorder. NCI Thesaurus. Code C92636.

A disorder characterized by an enduring pattern of avoidance of social situations and

interpersonal contact due to overwhelming feelings of social inadequacy and a

hypersensitivity to negative evaluation or rejection. 